\title{
A Conceptual Perspective on Mediating Competence in Sports Coaching and Physical Education
}

\author{
Tobias Vogt ${ }^{1,2}$, Daniel Klein ${ }^{3,4}$ \\ ${ }^{1}$ Institute of Professional Sport Education and Sport Qualifications, German Sport University, Cologne, Germany \\ ${ }^{2}$ Faculty of Sport Sciences, Waseda University, Tokorozawa, Japan \\ ${ }^{3}$ Institute of Sport Didactics and Physical Education, German Sport University, Cologne, Germany \\ ${ }^{4}$ Institute of Outdoor Sports and Environmental Science, German Sport University, Cologne Germany \\ Email: t.vogt@dshs-koeln.de, d.klein@dshs-koeln.de
}

How to cite this paper: Vogt, T., \& Klein, D. (2020). A Conceptual Perspective on Mediating Competence in Sports Coaching and Physical Education. Advances in Physical Education, 10, 187-195. https://doi.org/10.4236/ape.2020.103016

Received: May 11, 2020

Accepted: June 14, 2020

Published: June 17, 2020

Copyright $\odot 2020$ by author(s) and Scientific Research Publishing Inc. This work is licensed under the Creative Commons Attribution International License (CC BY 4.0).

http://creativecommons.org/licenses/by/4.0/

\begin{abstract}
Qualification and study programmes in sports coaching and physical education are based on concepts from Educational Sciences and, at least in part, Sports Sciences; established standards aim to didactically and methodologically educate best for an intended (e.g. learning objective) as well as setting-oriented (e.g. educational context) coaching or teaching, respectively. However, an often referred to mediating competence remains to be specified-if not, classified. Against the background of a categorizing approach on underlying terminological characteristics (i.e., skill, competence, literacy) and reviewing German education-related competence models, we suggest a conceptual perspective on an integrative mediating competence to serve sports coaching and physical education contexts.
\end{abstract}

\section{Keywords}

Skill Acquisition, Competency, Sport Literacy, Physical Literacy, Teaching, School Sport, Learning Objective, Training

\section{Introduction}

Today, an extensive use of terminologies such as skill, competence and literacy is omnipresent when aiming to determine educational and qualification standards (recently e.g. Young et al., 2019). Traditionally anchored in Educational Sciences, in Germany other disciplines such as Sports Sciences with its multidisciplinary approaches ranging from e.g. Training Sciences, Movement Sciences and Health Sciences to Social Sciences, add to the respective educational context to suggest 
sports-related qualification standards (frameworks, guidelines, curricula). In Germany alone, such concentrated expertise has led to a complex netting of terminologies (Gissel, 2013).

Set into international discourse, the present considerations refer to the "Framework for Qualification of the German Olympic Sports Confederation" (Sygusch et al., 2013 [Rahmenrichtlinien für Qualifizierung des Deutschen Olympischen Sportbundes, DOSB]) as well as to the "Core Curriculum for Secondary Education I in Grammar Schools of North Rhine-Westphalia-Sport" (MSB NRW, 2019 [Kernlehrplan für die Sekundarstufe I Gymnasium in Nordrhein-Westfalen-Sport]), not least to allow for a specification and, thus, serve an applied transfer.

Based on this, general aims are to:

1) Approach terminological characteristics of skill, competence and literacy and further suggest its (re)categorization, embedded into a didactical process and learning (mediating) objective;

2) Review education-related competence models with a particular focus of sports coaching and physical education to;

3) Suggest a conceptual perspective on an integrative mediating competence.

The following outlines claim not to be complete; however, it is intended to provide an overview to help classifying the present conceptual perspective on the basis of terminological characteristics as well as selected theories (models).

\section{Approaching Skill, Competence and Literacy}

The extensive use of terminologies such as skill, competence and literacy feed ongoing and evolving debates on both contextual classification as well as structural categorization not only in Educational Sciences but also within the scope of adjacent disciplines such as Sports Sciences with its respective qualification and study programmes (i.e., coaches' licensing, sports and physical education studies).

General understandings of sport literacy (Pill, 2010) or, seemingly the more prominent terminology in recent discourse, physical literacy (Jurbala, 2015; Whitehead, 2013; Young et al., 2019) categorize fundamental characteristics of a didactical process (i.e., how and what to achieve eventually) or learning objective (i.e., mediating objective according to intended and differentiated learning stages), being a matter of perspective as suggested in Figure 1. Previous research on physical literacy follow more motor developmental and behavioural approaches (McKean, 2013; Tompsett et al., 2014; e.g. tending towards a sport-specific movement learning and performance) or refer to a more comprehensive understanding on lifelong adherence to physical activity (Hastie \& Wallhead, 2015; e.g. similar to the curricula's educational concepts of school sport). Future directions on developing empirical measures of physical literacy have been presented (e.g. Giblin et al., 2014), whereas physical literacy assessments have been critically discussed (Robinson \& Randall, 2017). 


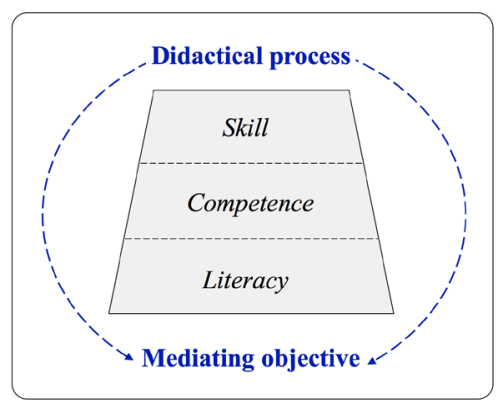

Figure 1. Perspectives of a didactical process and a learning objective (i.e., mediating objective) on a structural categorization of skill, competence and literacy.

However, sport literacy or physical literacy both require a distinct level of competence or competency. The coexisting use of the terminology competence on the one hand and competency on the other also follow different approaches: while competence refers to functional and demand-oriented educational contexts (Collins et al., 2015), competency seems to rather describe behavioural actions in less theory-driven and more practical educational contexts (Dooley \& Linder, 2002).

Accordingly, and in line with the displayed structure of Figure 1, competence or competency may derive from (practical) skill acquisition. Skill is often synonymously used as capability or the ability of an athlete, referring to an evidence-based process of skill acquisition in e.g. perceptual, cognitive and motor developments (Hodges \& Williams, 2012) or behaviour (Skrzeba \& Vogt, 2018). Additionally, skill acquisition, in a sport-specific educational context (i.e., learn-to-swim in children), has recently been indicated as the initial learning (developmental) stage in support of water competency that may lead to an aquatic literacy (Vogt \& Staub, 2020).

Following such understanding, the role of competence becomes crucial in sports-related educational contexts when evolving from separated skill acquisition processes towards a sport literacy (e.g. sport-specific) or physical literacy (e.g. comprehensive).

\section{Education-Related Competence Models}

Over decades, in particular Educational Sciences, and with respect to e.g. performance and movement learning in sports also Training Sciences, have suggested competence models for national (and international) qualification and study programmes that focus a physical education in schools (e.g. Bräutigam et al., 2005; Kehne et al., 2013; König, 2008; Terhart, 2002) or a more sport-specific coaching in clubs and federations (e.g. Strauch et al., 2019; Sygusch et al., 2017). The continuous conceptualisation, analyses and advancement of such competence models has led to a complex competence netting of, not least in Germany, established terminology including an e.g. acting, aesthetic, design, evaluation, health, media, methodological, movement, perception, personal, problem-solving, professional, reading, self- and self-regulation as well as social competence, which 
is not immune to criticism (Gissel, 2013). However, it seems reasonable that the variety of competence terminology, predominantly originating from one termintroducing competence model (Roth, 1971), serves educational guidelines in a sense of beneficial plurality (Schürmann, 2019).

Such profound understanding of competence on the one hand as well as a seemingly inflationary use of its terminology on the other hand (Stibbe, 2014), provide reason to further classify its educational contexts, not least, to identify intersections as well as differences, i.e. in guidelines for both sports coaching as well as teaching physical education.

\subsection{Sports Coaching}

The "Framework for Qualification of the German Olympic Sports Confederation" (Sygusch et al., 2013 [Rahmenrichtlinien für Qualifizierung des Deutschen Olympischen Sportbundes, DOSB]) set educational guidelines for all national sports federations and its clubs organized in the DOSB. Following a structured qualification process that aims to result in a staged licensing of each coach, four interlinked competences have been predefined (DSB, 2005; Sygusch et al., 2013):

- Personal [persönliche] and social-communicative competence [sozial-kommunikative Kompetenz] refers to capabilities on pedagogical acting in interpersonal situations, e.g. group leading or conflict management;

- Professional competence [Fachkompetenz] describes sport-specific expertise and ability, necessary for e.g. planning and evaluating processes of sporting activities;

- Methodological [Methoden-] and mediating competence [Vermittlungskompetenz] includes the knowledge of methods and models to e.g. execute training sessions;

- Strategic competence [strategische Kompetenz] means networking and organizational skills to e.g. modify structural processes.

Similar guidelines have been suggested on a European level within a "European Framework for the Recognition of Coaching Competence and Qualifications" (Duffy et al., 2010).

\subsection{Physical Education}

Within the federally organized educational system of Germany, subject-specific curricula (i.e., core curricula) have been defined for different school types, providing guidelines for acting as well as becoming teachers. The present conceptual perspective takes the "Core Curriculum for Secondary Education I in Grammar Schools of North Rhine-Westphalia-Sport” into consideration (MSB NRW, 2019); earlier versions of this core curriculum have been subject to conceptual reviews before (e.g. Vogt et al., 2019), not least because North Rhine-Westphalia is Germany's most populous federal state, schooling nearly 2.48 million pupils.

Herein, the pupils' learning objective aims for an acting competence [Handlungskompetenz] based on a movement competence [Bewegungskompetenz] and perception competence [Wahrnehmungskompetenz] amongst three inter- 
linked predefined competences (MSB NRW, 2019):

- Age-appropriate professional competence [Sachkompetenz] to e.g. understand physical activities or sports games and to form an objective position regarding subject-related problems;

- Methodological competence [Methodenkompetenz] includes methods and working procedures to e.g. self-dependently partake in physical activities or sports games;

- Evaluation competence [Urteilskompetenz] focusses on critically reflecting a sporting reality based on e.g. self-reliant and criteria-based assessments.

Reasonably, in both educational guidelines, regardless of its competence orientations, the mediator (i.e., coach, teacher) holds a responsible key role, providing a rational for a mediator-centred approach. Consequently, we suggest a more central anchoring of mediating competence, this conceptual perspective is based on todays' educational guidelines in German sport-specific coaching and physical education (i.e., the "Framework for Qualification of the German Olympic Sports Confederation" as well as the "Core Curriculum for Secondary Education I in Grammar Schools of North Rhine-Westphalia-Sport").

\section{A Conceptual Perspective}

Multi-layered competence orientations-ranging from more traditional healthrelated (e.g. Klein \& Vogt, 2019; Töpfer, 2017) to more recent digitalisationrelated (e.g. Vogt et al., 2019) competence orientations-are embedded into todays' educational guidelines for sports coaching as well as teaching physical education in Germany and form the rationale of the suggested conceptual perspective on a mediating competence.

\subsection{Mediating Competence}

Figure 2 suggests mediating competence arranged as core, embedded into complex interrelationships that include a personal competence and social competence (mediator-related) as well as methodological competence, evaluation competence and professional competence (education-related). It is important to note that,

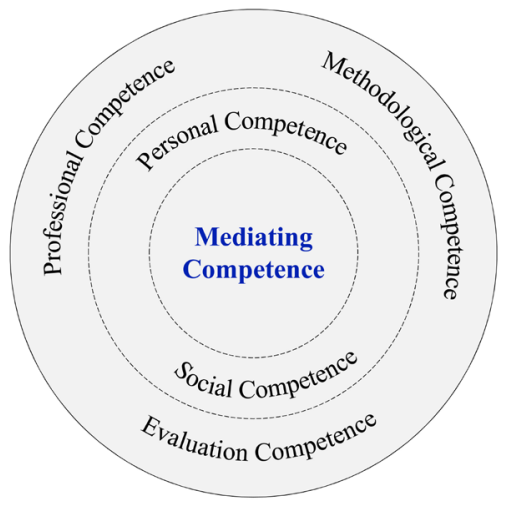

Figure 2. Classification of an integrative mediating competence in e.g. sports coaching and physical education. 
diffusing from the core outwards, all interrelationships of mediating competence are under continuous impact of e.g. topicality and innovation together with todays' increasing digitalisation serving as a didactic tool.

A mediator-related personal competence and social competence underline the mediator (e.g. coach, teacher) at focus. Personal competence is suggested to describe e. g. the mediation of values and attitude with authenticity and motivational aspects. Social competence is suggested to describe the mediation of e.g. respect, appreciation and esteem with empathy, patience, listening and communication.

These interrelationships are further complemented by education-related methodological competence, evaluation competence and professional competence. Methodological competence is suggested to describe a use of organisational and plannable but also flexible and reflective mediation models-interlinked to e. g. both motivational aspects and communication. Evaluation competence is suggested to describe diagnostics by means of recurrent observing and assessing as well as evaluating and feedback processes-interlinked to e.g. empathy, patience and listening. Professional competence is suggested to describe sport-specific expertise that is applied in both informed theory and safe practice-interlinked to e. g. authenticity.

In principle, an integrative mediating competence serves the learning objectives within a didactical process, suitable for the learning group as well as available infrastructural resources, respectively.

\subsection{Mediating Objective}

It seems important to note that the suggested conceptual perspective of an integrative mediating competence, no different from other models, serves intended learning objectives (i.e., mediating objectives).

Within each coaching or teaching process, a mediating objective determines any considered planning and implementation, e.g. in sporting activities and physical education. Suggested as annual periodisation, mediating objectives may be defined as short, medium and long-term objectives (Weineck, 2004). However, defining a mediating objective at any learning stage always relates to the learning group (e.g. pupils or university students, novices or professional athletes) as well as the respective educational context (e.g., school settings, recreational sporting activities, professional sports). Accordingly, multifaceted mediating concepts have been suggested to serve intended mediating objectives in sports coaching and, even more pronounced, physical education; this includes e.g. a playful concept (e.g. Dietrich et al., 2012 [Spielgemäßes Konzept]), an integrative gaming mediation (e.g. König, 2007; Roth \& Hahn, 2007 [Integrative Spielevermittlung]), Teaching Games for Understanding (TGfU; Bunker \& Thorpe, 1982; Griffin et al., 1997) and a genetic learning (e.g. Sinning, 2010 [Genetisches Lernen]). Further, reflection and evaluation methods are important, e.g. verbal communications (individual or in groups) and non-verbal approaches (e.g. learning logs); this, not least, puts the mediator (i.e., coach, teacher) at centre (again), responsible for a 
structural process as well as the contextual focus of each reflection and evaluation (Serwe-Pandrick, 2013), eventually aiming to achieve the intended mediating objective.

Following an intended mediating objective and, thus, aiming to apply an integrative mediating competence may benefit sports coaching and physical educational contexts.

\section{Conclusion}

The present conceptual perspective suggests an integrative mediating competence, resulting from different educational contexts (i.e., German coaches' licensing, sports and physical education studies as well as eventually physical education curricula) and, thus, different competence models while being embedded into a suggested linking category (i.e., competence) between skill acquisition processes and the objective of sport literacy or physical literacy.

To conclude, the suggested conceptual perspective on integrative mediating competence may underpin a (critical) reflection on the mediators' impact (i.e., personal competence and social competence of a coach or teacher) in educational contexts. With this, not only professional coaching or the developing of our (young) athletes in the respective national (and international) federations' talent promotion programmes may benefit; also, this may be relevant when coaching children in recreational sport clubs to mediate healthy sport-specific movements and performance. Last but not least and with respect to an intersection to schools' physical education, this may serve physical education teachers when mediating the joy of lifelong physical activities with all physical, mental and social benefits for our next generations' pupils.

Although not of particular relevance for the present conceptual perspective, it seems worth noting that future related research may find interest in systematically reviewing the ratios and reasoning of skill acquisition, (mediating) competence and sport literacy or physical literacy resulting from Educational Sciences and Sport Sciences previously addressing a sport-specific classification or sport by definition (e.g. Badminton, Football, Gymnastics, Swimming, Tennis).

\section{Conflicts of Interest}

The authors declare no conflicts of interest regarding the publication of this paper.

\section{References}

Bräutigam, M., Blotzheim, D., \& Swoboda, J. (2005). Acquisition of Competence in Physical Education Study. Mediating Professional and Self-Competence. In A. Gogoll, \& A. Menze-Sonneck (Eds.), Qualität im Schulsport. Schriften der Deutschen Vereinigung für Sportwissenschaft (Vol. 148, pp. 213-218). Hamburg: Czwalina.

Bunker, D., \& Thorpe, R. (1982). A Model for the Teaching of Games in Secondary Schools. Bulletin of Physical Education, 18, 5-8.

Collins, D., Burke, V., Martindale, A., \& Cruickshank, A. (2015). The Illusion of Competency versus the Desirability of Expertise: Seeking a Common Standard for Support 
Professions in Sport. Sports Medicine, 45, 1-7.

https://doi.org/10.1007/s40279-014-0251-1

Dietrich, K., Dürrwächter, G., \& Schaller, H. J. (2012). The Big Games. Basketball, Football, Handball \& Volleyball. Learn-to-Play Step-by-Step. Including Extensive Practical Part. Aachen: Meyer \& Meyer.

Dooley, K. E., \& Lindner, J. R. (2002). Competency-Based Behavioral Anchors as Authentic Tools to Document Distance Education Competencies. Journal of Agricultural Education, 43, 24-35. https://doi.org/10.5032/jae.2002.01024

DSB [Deutscher Sportbund] (2005). Framework for Qualifications in the German Sports Confederation. Frankfurt am Main: DSB.

Duffy, P., Crespo, M., \& Petrovic, L. (2010). The European Framework for the Recognition of Coaching Competence and Qualifications-Implications for the Sport of Athletics. IAAF New Studies in Athletics, 25, 27-41.

Giblin, S., Collins, D., \& Button, C. (2014). Physical Literacy: Importance, Assessment and Future Directions. Sports Medicine, 44, 1177-1184.

https://doi.org/10.1007/s40279-014-0205-7

Gissel, N. (2013). Of Doubters, Movement Culture Dreamers and the Real Sport Educational Survival Competence. Sportunterricht, 62, 264.

Griffin, L. L., Mitchell, S. A., \& Oslin, J. L. (1997). Teaching Sport Concepts and Skills-A Tactical Games Approach. Champaign: Human Kinetics.

Hastie, P. A., \& Wallhead, T. L. (2015). Operationalizing Physical Literacy through Sport Education. Journal of Sport and Health, 4, 132-138.

https://doi.org/10.1016/j.jshs.2015.04.001

Hodges, N. J., \& Williams, A. M. (2012). Skill Acquisition in Sport: Research, Theory and Practice (2nd ed.). London/New York: Routledge. https://doi.org/10.4324/9780203133712

Jurbala, P. (2015). What Is Physical Literacy, Really? Quest, 67, 367-383. https://doi.org/10.1080/00336297.2015.1084341

Kehne, M., Seifert, A., \& Schaper, N. (2013). Structure of an Instrument to Assess Competence in Physical Education Teacher Qualification. Sportunterricht, 62, 53-57.

Klein, D., \& Vogt, T. (2019). A Salutogenic Approach to Physical Education in Schools. Advances in Physical Education, 9, 188-196. https://doi.org/10.4236/ape.2019.93013

König, S. (2007). Integrative Education in Physical Education. INFO-Fachbereich Sport, 1, 8-10.

König, S. (2008). FESSKom-Or: A Concept to Educate Future Teachers. DSLV-Info, 3, 6-11.

McKean, M. (2013). Physical Literacy in Children-The Underpinning Movement Competencies. Journal of Sports Medicine and Doping Studies, 3, 2. https://doi.org/10.4172/2161-0673.1000e135

MSB NRW [Ministerium für Schule und (Weiter-)Bildung des Landes Nordrhein-Westfalen] (2019). Core Curriculum for Secondary Education I in Grammar Schools of North Rhine-Westphalia-Sport (No. 3426). Düsseldorf: MSB NRW.

Pill, S. (2010). Sport Literacy: It's Not Just about Learning to Play Sport via “Textbook Techniques". Journal of Student Wellbeing, 4, 32-42. https://doi.org/10.21913/JSW.v4i2.723

Robinson, D. B., \& Randall, L. (2017). Marking Physical Literacy or Missing the Mark on Physical Literacy? A Conceptual Critique of Canada's Physical Literacy Assessment Instruments. Measurement in Physical Education and Exercise Science, 21, 40-55.

https://doi.org/10.1080/1091367X.2016.1249793 
Roth, H. (1971). Pedagogical Anthropology. In Band II: Entwicklung und Erziehung. Grundlagen. Hannover: Schroedel.

Roth, K., \& Hahn, C. (2007). Integrative Game Mediation. INFO-Fachbereich Sport, 1, 4-7.

Schürmann, V. (2019). The e-Sport Case: How to Determine Sport? German Journal of Exercise and Sport Research, 49, 472-481. https://doi.org/10.1007/s12662-019-00622-0

Serwe-Pandrick, E. (2013). Learning by Doing and Thinking? On the Teaching Principle of a "Reflective Practice". Sportunterricht, 62, 100-106.

Sinning, S. (2010). Genetic Teaching and Learning-A Perceptual and Experience-Guided Method. In H. Lange, \& S. Sinning (Eds.), Handbuch Methoden im Sport (pp. 57-77). Balingen: Spitta.

Skrzeba, C., \& Vogt, T. (2018). A Cross-Educational Approach on Skill-Related Movement Technique Performance: Central Neuronal Motor Behaviour Preceding the Short Badminton Backhand Serve. Neuroscience Letters, 686, 155-160.

https://doi.org/10.1016/j.neulet.2018.09.005

Stibbe, G. (2014). Competence Orientation-Introducing the Issue. Sportunterricht, 63, 162.

Strauch, U. G., Wäsche, H., \& Jekauc, D. (2019). Coach Competences to Induce Positive Affective Reactions in Sport and Exercise: A Qualitative Study. Sports, 7, 16. https://doi.org/10.3390/sports7010016

Sygusch, R., Ahns, M., Bracher, B., Hapke, J., Liebl, S. \& Ptack, R. (2017). EKSpo: A Competence Draft for Sports-Related Educational Settings [EKSpo: Kompetenzentwurf für sportbezogene Bildungssettings]. In A. Schwirtz, F. Mess, Y. Demetriou, \& V. Senner (Eds.), Innovation \& Technologie im Sport. Schriften der Deutschen Vereinigung für Sportwissenschaft (Bd. 265, S. 235-239). Hamburg: Czwalina.

Sygusch, R., Liebl, S., \& Töpfer, C. (2013). Die Rahmenrichtlinien für Qualifizierung des Deutschen Olympischen Sportbundes-Einordnung in den Deutschen Qualifikationsrahmen für lebenslanges Lernen [Framework for Qualification of the German Olympic Sports Confederation]. In DOSB Deutscher Olympischer Sportbund (Eds.), Handreichung (pp. 1-37). Frankfurt am Main: DOSB.

Terhart, E. (2002). Standards for the Teacher Qualification. An Expertise for the Conference of Ministers of Education and Cultural Affairs. In ZKL-Texte (No. 24). Münster: Westfälische Wilhelms-University.

Tompsett, C., Burkett, B. J., \& McKean, M. R. (2014). Development of Physical Literacy and Movement Competency: A Literature Review. Journal of Fitness Research, 3, 53-74.

Töpfer, C. (2017). Sport-Related Health Competence: Competence Modelling and Test Development for Physical Education. PhD Thesis, Erlangen-Nuremberg: FriedrichAlexander-University.

Vogt, T., \& Staub, I. (2020). Assessment of Basic Aquatic Skills in Children: Inter-Rater Reliability of Coaches, Teachers, Students and Parents. Journal of Physical Education and Sport, 20, 577-583.

Vogt, T., Rehlinghaus, K., \& Klein, D. (2019). School Sport Facing Digitalisation: A Brief Conceptual Review on a Strategy to Teach and Promote Media Competence Transferred to Physical Education. Journal of Physical Education and Sport, 19, 1424-1428.

Weineck, J. (2004). Optimal Training. Performance-Physiological Training Theory with Special Consideration of Children and Youth Training. Balingen: Spitta.

Whitehead, M. (2013). Definition of Physical Literacy and Clarification of Related Issues. ICSSPE Bulletin, 65, 29-35.

Young, L., O’Connor, J., \& Alfrey, L. (2019). Physical Literacy: A Concept Analysis. Sport, Education and Society. https://doi.org/10.1080/13573322.2019.1677586 